\title{
Ten Years of VINQUEST: First Insight for Breeding New Apple Cultivars With Durable Apple Scab Resistance
}

\begin{abstract}
Andrea Patocchi, ${ }^{1, \dagger}$ Andreas Wehrli, ${ }^{1}$ Pierre-Henri Dubuis, ${ }^{2}$ Annemarie Auwerkerken, ${ }^{3}$ Carmen Leida, ${ }^{4}$ Guido Cipriani, ${ }^{5}$ Tom Passey, ${ }^{6}$ Martina Staples, ${ }^{7}$ Frédérique Didelot, ${ }^{8}$ Vincent Philion, ${ }^{9}$ Andreas Peil, ${ }^{10}$ Hannes Laszakovits, ${ }^{11}$ Thomas Rühmer, ${ }^{12}$ Klemens Boeck, ${ }^{13}$ Danas Baniulis, ${ }^{14}$ Klaus Strasser, ${ }^{15}$ Radek Vávra, ${ }^{16}$ Walter Guerra, ${ }^{17}$ Sylwester Masny, ${ }^{18}$ Franz Ruess, ${ }^{19}$ Fanny Le Berre, ${ }^{20}$ Hilde Nybom, ${ }^{21}$ Stefano Tartarini, ${ }^{22}$ Andreas Spornberger, ${ }^{23}$ Anna Pikunova, ${ }^{24}$ and Vincent G. M. Bus ${ }^{25}$
\end{abstract}

${ }^{1}$ Agroscope, Breeding Research, 8820 Wädenswil, Switzerland

2 Agroscope, Plant Protection, 1260 Nyon, Switzerland

${ }^{3}$ Better3fruit, 3202 Rillaar, Belgium

${ }^{4}$ Consorzio Italiano Vivaisti CIV, 44022 San Giuseppe di Comacchio, Italy

${ }^{5}$ Dipartimento di Scienze Agroalimentari, Ambientali e Animali, University of Udine, 33100 Udine, Italy

${ }^{6}$ NIAB EMR, East Malling, West Malling ME19 6BJ, United Kingdom

${ }^{7}$ Höhere Bundeslehranstalt und Bundesamt für Wein- und Obstbau Klosterneuburg, 3400 Klosterneuburg, Austria

${ }^{8}$ IRHS, Agrocampus-Ouest, INRA, Université d'Angers, 49071 Beaucouzé, France

${ }^{9}$ Institut de Recherche et de Développement en Agroenvironnement, Saint-Bruno-de-Montarville, QC J3V 0G7, Canada

${ }^{10}$ Julius Kühn-Institut (JKI), Bundesforschungsinstitut für Kulturpflanzen, Institut für Züchtungsforschung an Obst, 01326 Dresden, Germany

${ }^{11}$ Landwirtschaftliche Fachschule Eisenstadt, 7000 Eisenstadt, Austria

${ }^{12}$ Versuchsstation Obst- und Weinbau Haidegg, 8047 Graz, Austria

${ }^{13}$ Landwirtschaftskammer Tirol, 6020 Innsbruck, Austria

${ }^{14}$ Lithuanian Research Centre for Agriculture and Forestry, 54333 Babtai, Lithuania

${ }^{15}$ Obst-Sorten-Garten Ohlsdorf, 4694 Ohlsdorf, Austria

${ }^{16}$ Research and Breeding Institute of Pomology, Holovousy 129, 50801 Horice, Czech Republic

${ }^{17}$ Laimburg Research Centre, Laimburg 6, 39040 Ora, Italy

${ }^{18}$ Research Institute of Horticulture, Skierniewice, Poland

${ }^{19}$ Staatliche Lehr- und Versuchsanstalt für Wein und Obstbau Weinsberg, 74189 Weinsberg, Germany

${ }^{20}$ Station d'études et d'expérimentations fruitières de La Morinière, La Morinière, 37800 Saint Epain, France

${ }^{21}$ Swedish University of Agricultural Sciences, Balsgård, 29194 Kristianstad, Sweden

${ }^{22}$ Department of Agricultural and Food Sciences, University of Bologna, 40126 Bologna, Italy

${ }^{23}$ University of Natural Resources and Life Sciences, Vienna, Austria

${ }^{24}$ VNIISPK - Russian Research Institute of Fruit Crop Breeding, 302530 Zilina, Russia

${ }^{25}$ The New Zealand Institute for Plant and Food Research Limited, 4157 Havelock North, New Zealand

\begin{abstract}
Apple scab, caused by Venturia inaequalis, is a major fungal disease worldwide. Cultivation of scab-resistant cultivars would reduce the chemical footprint of apple production. However, new apple cultivars carrying durable resistances should be developed to prevent or at least slow the breakdown of resistance against races of $V$. inaequalis. One way to achieve durable resistance is to pyramid multiple scab resistance genes in a cultivar. The choice of the resistance genes to be combined in the pyramids should take into account the frequency of resistance breakdown and the geographical distribution of apple scab isolates able to

from 14 countries regularly contribute data. From 2009 to 2018, nearly 9,000 data points have been collected. This information has been used to identify the most promising apple scab resistance genes for developing cultivars with durable resistance, which to date are: Rvi5, Rvi11, Rvi12, $R v i 14$, and Rvil5. As expected, Rvil, together with Rvi3 and Rvi8, were often overcome, and have little value for scab resistance breeding. Rvilo may also belong to this group. On the other hand, Rvi2, Rvi4, Rvi6, Rvi7, $R v i 9$, and $R v i 13$ are still useful for breeding, but their use is recommended only in extended pyramids of $\geq 3$ resistance genes.
\end{abstract} cause such breakdowns. In order to acquire this information and to make it available to apple breeders, the VINQUEST project (www.vinquest.ch) was initiated in 2009. Ten years after launching this project, 24 partners

Keywords: Venturia inaequalis, apple breeding, apple scab, durable resistance, molecular marker, virulence

Apple scab, caused by the ascomycete fungus Venturia inaequalis, is a major fungal disease in most temperate growing regions around the world, requiring many fungicide applications. Generally, up to 15

${ }^{\dagger}$ Corresponding author: A. Patocchi; andrea.patocchi@agroscope.admin.ch

The author(s) declare no conflict of interest.

Accepted for publication 25 February 2020.

(c) 2020 The American Phytopathological Society applications of fungicides are necessary to control the disease (MacHardy 1996). However, in some areas with high precipitation and high disease pressure, 20 to 30 applications may be required when growing susceptible cultivars (Manktelow et al. 1996), thereby increasing the risk of fungicide breakdown (Ayer et al. 2019; Chapman et al. 2011; Frederick et al. 2014). This problem may have been further exacerbated through integrated pest management strategies aimed at reducing fungicide inputs for disease control (Beckerman et al. 2015). While some efficacy may still be achieved for these fungicides (van den Bosch et al. 2018), application of complementary strategies for disease control, such as orchard sanitation measures, 
is essential. Thus, leaf litter management (Holb 2006, 2007; Mac an tSaoir et al. 2010; Porsche et al. 2017) assists in reducing the disease pressure and the risk of fungicide breakdown. Growing scabresistant cultivars could be an additional contributor to more sustainable apple production, provided that the resistance is durable. Unfortunately, most of the scab-resistant cultivars released to date carry only one gene, Rvi6 (Vf), and its value is questionable since avrRvi6 isolates now occur all over Europe (Bengtsson et al. 2000; Lefrancq and Lateur 2009; Parisi et al. 2004) and have also been observed in the U.S.A. (Beckerman et al. 2009; Papp et al. 2020). Isolates virulent to other Rvis were identified early on in the Purdue-RutgersIllinois back-cross program for Rvi2 (Vh2) and Rvi4 (Vh4) (Williams and Shay 1957) and Rvi5 (Vm) (Williams and Brown 1968). Today, virulent isolates have been shown to exist for most of the scab resistance genes used in apple breeding, including some carrying multiple virulence (Bus et al. 2011; Caffier et al. 2015; Peil et al. 2018). These findings accentuate the need for breeding for durable resistance.

A common strategy to achieve durable resistance is through pyramiding resistance genes, augmented by marker-assisted selection (MAS) technology (Vanderzande et al. 2018). The availability of a diverse range of resistance genes, enabling multiple combinations, greatly assists in the successful application of this strategy. To date, many scab resistance genes are known, of which 19 have been included in the Rvi nomenclature system (Bus et al. 2011; Gardiner et al. 2018; Soriano et al. 2014). Therefore, genetic markers for most of these genes, preferably cheap high-throughput single nucleotide polymorphism (SNP) and competitive allele-specific PCR (CASP) markers (Baumgartner et al. 2016; Jänsch et al. 2015), are available for MAS. Also, breeding parents carrying resistance genes in a homozygous state, e.g., Rvi2, Rvi4, and Rvi6, have been developed (Baumgartner et al. 2015), which increases breeding efficiency and reduces the need for MAS as $100 \%$ of the progeny are resistant.

Hitherto not utilized resistance genes are available in wild apple germplasm. Fast-breeding technologies may be required to rapidly transfer these into elite germplasm, e.g., physiological (Volz et al. 2009) and/or genetic modification approaches, such as early flowering (Flachowsky et al. 2011; Schlathölter et al. 2018). In the U.S.A., null segregants (i.e., the final products of the early flowering system that do not carry the fast-flowering gene) are exempted from regulations concerning genetically modified organisms, as long as these genotypes have been shown, with molecular methods, to not contain transgenes or pieces of transgenes (Firko 2014; Gregoire 2011; McGarry et al. 2017).

With markers available for a range of resistance genes and the ability to create new cultivars with gene pyramids, the next step is to identify the most desirable gene combinations for different geographic regions. The VINQUEST project was initiated 10 years ago (Patocchi et al. 2009; www.vinquest.ch) to collect information on the geographical distribution of (a)virulence genes in $V$. inaequalis populations, following in the tradition of virulence monitoring in, for example, rust diseases in cereals (Kosman et al. 2019; PaczosGrzęda and Sowa 2019). The VINQUEST project takes a systematic worldwide approach, extending on the standalone monitoring previously performed in a number of locations (e.g., Bengtsson et al. 2000; Lefrancq and Lateur 2009; Lespinasse 1989; Sandskär and Liljeroth 2005). A set of differential apple hosts carrying a range of scab resistance genes was developed based on the work of Bus et al. (2011) and distributed to partners around the world. In this paper, we report on the observations made at 24 trap orchards to date.

\section{Materials and Methods}

The 16 differential Malus hosts, representing a range of apple scab resistance genes including one host, $\mathrm{h}(0)$, not carrying any scab resistance genes of breeding value, had been selected previously (Table 1; Patocchi et al. 2009). Budwood of these genotypes was provided free of charge to the project participants. Each partner was free to design their own experimental orchard, but the planting of five blocks, each containing one tree of each differential host as well as five "placeholders" in a randomized fashion, was advised. The placeholders are apple scab-susceptible genotypes to be substituted once new differential hosts become available. At some sites, few differential hosts were missing because of unsuccessful grafting. This was the case for 11 differential hosts (Table 1), but in particular for host (11), M. baccata 'Jackii,' which is present in only 17 out of the 24 possible sites. It was observed that budding of $h(11)$ in late summer leads to a higher success rate compared with bench grafting in winter.

No fungicides were applied at any time before scoring. Afterward, application of fungicides was allowed if needed in order to protect the trees from too much damage, which might jeopardize their survival and growth until the following season.

Incidence and severity of scab on the leaves of each tree was scored on a 1 to 9 scale at the end of each apple scab primary season (Patocchi et al. 2009; Fig. 1). Only strongly sporulating lesions without resistance reactions by the host observed on young leaves (i.e., fully compatible interaction) were considered as a resistance gene breakdown. Resistance gene breakdown was documented with digital photographs. Scoring values, photographs, and in a few cases, affected leaves were sent to the coordinator (Agroscope) for validation of the observations. If doubts remained over the resistance gene breakdown being complete, the "in dubio pro reo" rule was applied in favor of the host; doubtful lesions were not considered as a compatible interaction and the calls were revised to disease severity score 1 (i.e., no symptoms).

An observation was defined as the score of a tree in a location (site) in a specific year. If all the observations in a specific year and locations were equal to "1", i.e., no scab found, none of the observations of this location and year were considered for this study, due to unconducive weather conditions for scab infection. This occurred only three times: Ora (Italy) in 2017 and 2018 and Kristianstad (Sweden) in 2016. Rvi genes were divided into categories based on the frequency of their breakdown over the total number of observations, or the frequency of sites in which an Rvi breakdown was observed at least once over the total number of sites in which the corresponding differential host had been planted. The categories were defined as follows: "often overcome," breakdown observed in more than $50 \%$ of the observations or sites; "frequently overcome," breakdown observed in 31 to $50 \%$ of the observations or sites; "sometimes overcome," breakdown observed in 16 to $30 \%$ of the observations or sites; "rarely overcome," breakdown observed in up to $15 \%$ of the observations or sites; "not overcome," breakdown not observed. The same categories were used independently of the threshold set to call an $R v i$ gene breakdown (i.e., scores $\geq 2$ or $>2$ ).

\section{Results}

Since the start of VINQUEST 10 years ago, 24 partners from 14 countries have joined the monitoring of apple scab resistance gene breakdown and provide data (see affiliation list of the coauthors of this paper). Another 15 partners in an additional nine countries are presently establishing their differential orchards, while nine more partners in a further three countries have declared an interest in joining the project, but for different reasons have not yet done so (see www.vinquest.ch).

To date, nearly 9,000 data points have been collected (Fig. 1) and these were used to extract the first trends. Since the determination of a resistance gene breakdown is not always clear-cut, we used several approaches to interpret the collected data. In the first approach, all data were considered independently from observation site. Based on the number of disease severity scores $\geq 2$ as a ratio of the total number of observations for each differential host, the hosts were assigned to a frequency category. Scab resistance genes Rvil, Rvi3, and Rvi8 fell in the category "often overcome", and Rvi6, Rvi7, and Rvilo in the category "sometimes overcome". Seven genes, Rvi2, Rvi4, Rvi5, Rvi9, Rvi12, Rvi13, and Rvi14, were assigned to the category "rarely overcome," while Rvi11 and Rvi15 were assigned to the category "not overcome" since no compatible interactions were observed on their hosts to date (Table 1).

Our second approach to interpret the data without taking sites into consideration was to place the threshold to call an $R v i$ gene breakdown a disease severity class 3 score. Class 3 scores are defined as "Immediately apparent lesions generally clustered in a few parts of 
the tree (1-5\% of leaves affected)." Starting from this class, the scab symptoms are generally obvious. Using this threshold, Rvil remains in the category "often overcome," while Rvi3 and Rvi8 move to the category "frequently overcome." Genes Rvi6, Rvi7, and RvilO also change category and are now together with Rvi2, Rvi4, Rvi5, Rvi9, Rvi12, Rvi13, and Rvil4 in the category "rarely overcome." Obviously, Rvil1 and Rvil5 stay in category "not overcome" (Table 1).

Our third approach was to quantify the frequency of $R v i$ breakdowns over the different sites (Table 1). We considered an Rvi gene to be overcome at a specific site each time at least one class 3 score was called. This approach grouped the Rvi genes as follows: Rvil, Rvi3, Rvi8, and Rvilo fell in the category "often overcome;" Rvi2, Rvi4, Rvi6, Rvi7, Rvi9, and Rvil3 in "sometimes overcome;" Rvi5, Rvi12, and Rvil4 in "rarely overcome," and again Rvil1 and Rvi15 in the category "not overcome."

The fourth approach combines the frequency of scores $>2$ with the frequency with which these scores had been given in the different sites (Table 1). For Rvi1, Rvi3, and Rvi8, observations of scores $>2$ occurred often or frequently, and these were also found in many of the sites. Rvil0 rarely obtained scores $>2$, but such scores were nevertheless present in about half of the sites (category "often"). A relatively large group of genes, i.e., Rvi2, Rvi4, Rvi6, Rvi7, $R v i 9$, and $R v i 13$, were rarely scored $>2$, but such scores were still given in about a quarter of the sites (category "sometimes"). Finally, Rvi5, Rvi12, and Rvil4 rarely received scores $>2$ at any site (category "rarely").

Update on the differential hosts. The VINQUEST project is a work in progress as new differential hosts are identified following genetic studies on new scab resistance genes. Here we present an update for a number of scab resistance genes and their representative differential hosts, three of which are currently being multiplied for distribution among the VINQUEST participants.

Host (3). The current differential h(3) accession Q71 was selected from a 'Geneva' $\times$ 'Braeburn' family based on the assumption that it carried one of the two or three genes described in early reports on the 'Geneva' scab resistance (Bus et al. 2011). Later, this resistance was shown to be more complex and to contain a cluster of five genes, each with a moderate resistance spectrum, mapping to linkage group 4 (LG4) of this cultivar (Bastiaanse et al. 2016). Also, 'Geneva' itself has been reported to show scab symptoms (Beckerman et al. 2009; Bengtsson et al. 2000; Sandskär and Liljeroth 2005), although it performed well in a long-term Belgian study (Lefrancq and Lateur 2009). To determine whether this is the case for other sites as well, we will revert to using 'Geneva' as h(3) (Lespinasse 1994) in V. inaequalis monitoring for subsequent years, while avoiding overloading the trap orchards with differential hosts representing its individual genes that on their own have little value for breeding.

Host (7). To date, in the absence of a specific $h(7)$ only carrying the Rvi7 gene, host (6,7) Malus floribunda 821 was used as it is the original source of the gene (Bénaouf and Parisi 1997, 2000). Following the mapping of the gene to LG8 of M. floribunda 821 (Durel et al. 2006), progeny LPG3-29 was selected as $h(7)$. In a study with a limited number of isolates, nine out of 21 isolates were compatible with h(7) (Caffier et al. 2015), while M. floribunda 821 was found infected in a number of studies (Bengtsson et al. 2000; Lefrancq and Lateur 2009; Roberts and Crute 1994; Sandskär and Liljeroth 2005; this study). Like 'Geneva,' LPG3-29 will be monitored for a number of years in order to assess its breeding value.

Host (9). Initially, the host-pathogen interaction of $V$. inaequalis race $(1,2,8,9)$ isolate 1639 with progeny $\mathrm{J} 34$ selected from a 'Gala' $\times$ 'Dolgo' family, was rated as compatible (Broggini et al. 2011) and interpreted as confirming the ability of this isolate to overcome Rvi9. However, later reinterpretation concluded that the interaction was incompatible, with a weak, sporulating resistance reaction suggesting the presence of a partial resistance gene. This was further substantiated when $V d g 2$ was shown to segregate as a single gene in a 'Golden Delicious' $\times$ K108 progeny inoculated with $V$. inaequalis isolate 1639 (which is compatible with Rvil [Caffier et al. 2015]). In contrast, 1639 showed a virulent phenotype with unlimited sporulation (compatible interaction) on accession $\mathrm{K} 2$ as well as on nearly all 'Gala' $\times$ K2 progeny, confirming K2 to be the preferred host (9) (V. G. M. Bus, unpublished data). An additional practical reason to change the genotype representing $\mathrm{h}(9)$ is that $\mathrm{J} 34$ has been growing poorly at several sites. The leaves often are chlorotic and fold along the main vain, making scab assessment difficult.

Host (16). The scab resistance of the open-pollinated MIS (mildew immune seedling) derivative 93.051 G07-098 was mapped as a single gene, Rvi16, to LG3 (Bus et al. 2010). With the aid of the microsatellite markers NH030a and NZmsCN943818, it was shown that the gene originated from MIS. However, further genetic studies with the openpollinated MIS derivative since indicated that it contains at least one more scab resistance gene from either MIS or the unknown pollen parent. While awaiting completion of the genetic studies, MIS itself will be added to the differential host set for distribution to the trap orchards.

Host (17). Multiple studies over the years have shown that the 'Antonovka' scab resistance is complex, with a number of its

Table 1. Differential apple hosts carrying specific $R v i$ scab resistance genes ranked according to the percentage of resistance breakdown (class $\geq 2$ ) and the frequency of such events over the sites that have provided data to date

\begin{tabular}{|c|c|c|c|c|c|c|c|c|}
\hline $\begin{array}{l}\text { Differential } \\
\text { host }\end{array}$ & Genotype & Rvi gene & Old name & $\begin{array}{c}\text { Total } \\
\text { observations }\end{array}$ & $\begin{array}{c}\text { Total obs. } \\
\text { score } \geq 2(\%)\end{array}$ & Category ${ }^{\mathbf{a}}$ & $\begin{array}{c}\begin{array}{c}\text { Total } \\
\text { obs. }\end{array} \\
\text { score }>2(\%)\end{array}$ & Category ${ }^{\mathbf{a}}$ \\
\hline $\mathrm{h}(0)$ & Gala & None & - & 601 & $540(89.9)$ & often & $476(79.27)$ & often \\
\hline$h(1)$ & Golden Delicious & Rvil & $V g$ & 609 & $550(90.3)$ & often & $488(80.1)$ & often \\
\hline $\mathrm{h}(3)$ & Q71 & Rvi3 & Vh3.1 & 582 & $344(59.1)$ & often & $252(43.3)$ & frequently \\
\hline $\mathrm{h}(8)$ & B45 & Rvi8 & Vh8 & 603 & $388(64.3)$ & often & $268(44.4)$ & frequently \\
\hline $\mathrm{h}(10)$ & A723-6 & Rvilo & $V a$ & 574 & $159(27.7)$ & sometimes & 67 (11.7) & rarely \\
\hline$h(6)$ & Priscilla & Rvi6 & $V f$ & 575 & $95(16.5)$ & sometimes & $69(12.0)$ & rarely \\
\hline$h(6,7)$ & M. floribunda 821 & Rvi6, Rvi7 & $V f, V f h$ & 515 & $98(19.0)$ & sometimes & $74(14.4)$ & rarely \\
\hline $\mathrm{h}(13)$ & Durello di Forlì & Rvil3 & $V d$ & 495 & $76(15.4)$ & rarely & $25(5.1)$ & rarely \\
\hline $\mathrm{h}(2)$ & TSR34T15 & Rvi2 & Vh2 & 537 & $62(11.5)$ & rarely & $23(4.3)$ & rarely \\
\hline $\mathrm{h}(4)$ & TSR33T239 & Rvi4 & $V h 4$ & 567 & $27(4.8)$ & rarely & $14(2.5)$ & rarely \\
\hline $\mathrm{h}(9)$ & $\mathrm{J} 34$ & $R v i 9$ & $V d g$ & 602 & $49(8.1)$ & rarely & $14(2.3)$ & rarely \\
\hline$h(14)$ & Dülmener Rosenapfel & Rvil4 & $V d r 1$ & 565 & $16(2.8)$ & rarely & $3(0.5)$ & rarely \\
\hline $\mathrm{h}(5)$ & 9-AR2T196 & Rvi5 & $V m$ & 551 & $27(4.9)$ & rarely & $11(2.0)$ & rarely \\
\hline $\mathrm{h}(12)$ & Hansen's baccata 2 & Rvi12 & $V b$ & 569 & $3(0.5)$ & rarely & $1(0.2)$ & rarely \\
\hline $\mathrm{h}(11)$ & M. baccata 'Jackii' & Rvill & $V b j$ & 287 & 0 & not overcome & $0(0)$ & not overcome \\
\hline $\mathrm{h}(15)$ & GMAL2473 & Rvi15 & $V r 2$ & 582 & 0 & not overcome & $0(0)$ & not overcome \\
\hline \multicolumn{9}{|c|}{ (Continued on next page) } \\
\hline
\end{tabular}

\footnotetext{
a Often overcome: breakdown (class $\geq 2$ or $>2$ ) observed on more than $50 \%$ of the observations or sites; frequently overcome: breakdown (class $\geq 2$ or $>2$ ) observed between 50 and $31 \%$ of the observations or sites; sometimes overcome: breakdown (class $\geq 2$ or $>2$ ) observed between 30 and $16 \%$ of the observations or sites; rarely overcome: breakdown (class $\geq 2$ or $>2$ ) observed between 1 and $15 \%$ of the observations or sites; not overcome: breakdown not observed.
} 
progeny that have been used as breeding parents carrying different components of the resistance (Bus et al. 2012). The parents used in many breeding programs appear to have derived from 'Common Antonovka,' also known as 'Schmidt's Antonovka' (Pikunova et al. 2014), since Schmidt widely distributed progeny from his genetic studies on scab resistance (Bus et al. 2012). The progeny mostly showed a hypersensitive response (HR) or chlorotic (Chl) resistance reactions (Brauns 1962). Currently in VINQUEST, the gene conditioning HR is associated with differential host (10), represented by accession A723-6 derived from the original Rvilo source PI 172623 (Bus et al. 2012). This may be the same gene as the HRconditioning Va2 gene mapped to a similar region, about $14 \mathrm{cM}$ above the Rvi6 region on LG1 in 'Antonovka' APF22 (Dunemann and Egerer 2010). The second, Chl-conditioning gene from 'Antonovka' APF22 was mapped to the Rvi6 region but shown to be different from Rvi6. The gene was named Rvil7 (Dunemann and Egerer 2010) and recently the genotype 04/214-079 from the 'Golden Delicious' $\times$ 'Antonovka' APF22 family was made available for distribution in the VINQUEST project. Nevertheless, further research is required to elucidate the genetic relationships of the Rvil0 and Rvil7 genes with those in other related 'Common Antonovka' derivatives, such as CCR1T8 and CCR3T11 (Lespinasse 1989), 'Freedom' (Zini 2005), and TN10-8 (Calenge et al. 2004).

Host (18). Rvil8 has been identified in genotype 1980-015-025 (Soriano et al. 2014). Since it also carries the narrow spectrum $V d 3$ scab resistance gene (Soriano et al. 2009), a progeny of 1980-015025 only carrying Rvil 8 would be the natural differential host for this gene. Since no genotype will be made available unconditionally at this stage, we refrain from including $\mathrm{h}(18)$ trees in the trap orchard.

Hosts (19) and (20). Anticipating broad-spectrum genes to control scab resistance in 'Honeycrisp,' the denotations Rvil9 and Rvi20 were initially assigned to the two scab resistance genes identified in this cultivar (Clark 2014; Clark et al. 2014), and repeated in a number of publications (e.g., Igarashi et al. 2016; Khajuria et al. 2018). However, the Rvi assignments turned out to have been premature as more information became available. With the gene identified as Rvi19 mapping to the same region on LG1 as the Chl-conditioning 'Common Antonovka' and showing the same $\mathrm{CH}-\mathrm{Vf1}-139$ bp allele (Clark 2014), their genetic relationships need to be elucidated. The gene identified as Rvi2O and mapping to LG15 of 'Honeycrisp' appears to have a narrow spectrum, hence its breeding value is too low for inclusion in the trap orchard evaluation network. Henceforth, the genes have been assigned $V h c l$ and $V h c 15$ as working names, with $h c$ referring to 'Honeycrisp' and the numbers to the LG they map. In the meantime, Rvi19 has now been assigned to a third scab resistance gene from Russian apple R12740-7A (Gardiner et al. 2018). Differential hosts for Rvi19 and Rvi20 will be included in the $V$. inaequalis population monitoring in due course.

\section{Discussion}

The VINQUEST initiative has started well and the network continues to expand. Over the first 10 years of $R v i$ monitoring activities, sufficient data have been collected to identify the first trends. Different interpretations of the collected data have been presented, setting different thresholds to call a resistance gene breakdown; i.e., severity scores (sometimes in the text also called classes for simplicity) $\geq 2$ or $>2$, and grouping the Rvis in categories.

Our first approach defined the threshold to call an Rvi breakdown as starting from the identification of a few sporulating apple scab lesions without detection of any resistance reaction upon scrutiny of the tree (severity class 2). This class is the most prone to falsepositive errors. While inspecting a tree, necrotic flecks on leaves may be erroneously interpreted as old apple scab lesions instead of being recognized as an expression of partial resistance. Such flecks may also be due to other fungi. Due to the awareness of these possible sources of mistakes, class 2 scores were carefully scrutinized during the validation process of checking the photographs and/or the leaves provided. When doubts remained about putatively affected leaves, the class 2 calls were revised to class 1 (application of the in dubio pro reo rule) to minimize the risk of calling false resistance breakdowns, so as not to discourage apple breeders from investing in some very valuable resistance sources

In order to reduce the risk of false calls, we propose considering a resistance gene breakdown from class 3 only. Starting from this class, apple scab symptoms are sufficiently abundant and obvious, so fewer mistakes can be expected. The change of threshold from class 2 to class 3 resulted in a shift of some $R v i$ genes to lower categories; two of them (Rvi3 and Rvi8) moved into the category "frequently overcome," while another four (Rvi6, Rvi7, Rvi10, and Rvi13) moved into the category "rarely overcome." Rvi3 and Rvi8 still remain in a category with quite high frequencies of resistance gene breakdown, agreeing with similar earlier findings for the original host (3), 'Geneva' (Bengtsson et al. 2000; Sandskär and Liljeroth 2005), although less so with a Belgian study where infections on this host were mostly

Table 1. (Continued from previous page)

\begin{tabular}{|c|c|c|c|c|c|}
\hline $\begin{array}{l}\text { Differential } \\
\text { host }\end{array}$ & $\begin{array}{l}\mathrm{N}^{\circ} \text { sites with } \\
\text { class } 2 \text { scores but } \\
\text { not higher }\end{array}$ & $\begin{array}{l}\text { Frequency }(\%) \text { of } \\
\text { class } 2 \text { scores but } \\
\text { not higher }\end{array}$ & $\mathrm{N}^{\circ}$ sites with scores $>2$ & $\begin{array}{l}\text { Frequency }(\%) \\
\text { of sites with } \\
\text { scores }>2\end{array}$ & Category $^{\mathbf{a}}$ \\
\hline $\mathrm{h}(0)$ & 0 & 0 & 24 & 100 & often \\
\hline $\mathrm{h}(1)$ & 0 & 0 & 24 & 100 & often \\
\hline $\mathrm{h}(3)$ & 2 & 8 & 20 & 83 & often \\
\hline $\mathrm{h}(8)$ & 3 & 13 & 21 & 88 & often \\
\hline $\mathrm{h}(10)$ & 4 & 17 & 13 & 57 & often \\
\hline$h(6)$ & 2 & 8 & 7 & 29 & sometimes \\
\hline$h(6,7)$ & 1 & 4 & 6 & 26 & sometimes \\
\hline$h(13)$ & 4 & 19 & 6 & 29 & sometimes \\
\hline $\mathrm{h}(2)$ & 4 & 17 & 7 & 30 & sometimes \\
\hline $\mathrm{h}(4)$ & 1 & 4 & 6 & 26 & sometimes \\
\hline $\mathrm{h}(9)$ & 9 & 39 & 5 & 22 & sometimes \\
\hline$h(14)$ & 7 & 30 & 3 & 13 & rarely \\
\hline$h(5)$ & 2 & 9 & 1 & 4 & rarely \\
\hline $\mathrm{h}(12)$ & 1 & 4 & 1 & 4 & rarely \\
\hline $\mathrm{h}(11)$ & 0 & 0 & 0 & 0 & not overcome \\
\hline$h(15)$ & 0 & 0 & 0 & 0 & not overcome \\
\hline
\end{tabular}


restricted to fruit (Lefrancq and Lateur 2009). Therefore, these two genes (together with Rvil) are de facto of low interest for breeding cultivars to be deployed in regions covered by the current VINQUEST network, until proof is provided that they do have a role to play in scab gene pyramids. The shift of the other four genes may lead to different conclusions about their value in plant breeding. For Rvilo and Rvi13, frequency of resistance gene breakdown calls was reduced by between 60 and $75 \%$, and by between 25 and $30 \%$ for $R v i 6$ and $R v i 7$. This indicates a relatively high frequency of class 2 calls for Rvilo and Rvi13, but fewer for Rvi6 and Rvi7.

During the monitoring, we observed that scab infection of host $(6,7)$ M. floribunda 821 often resulted in high severity scores, in accordance with previous findings (e.g., Bengtsson et al. 2000; Roberts and Crute 1994; Sandskär and Liljeroth 2005), suggesting that this genotype does not have any additional resistances. Rvi6 is the most frequently used resistance gene in apple breeding. Cultivars carrying this resistance have been planted in limited numbers in many European countries for more than 40 years. Unfortunately, avrRvi6 isolates are known to be present in multiple regions of Europe (Bengtsson et al. 2000; Lefrancq and Lateur 2009; Parisi et al. 2004), and over time they have recombined and so possibly have acquired additional virulences, enlarging the range of genotypes that they are able to infect (Caffier et al. 2015).
The change of threshold from class 2 to class 3 resulted in considerable reductions of breakdown calls for the $R v i$ genes in the category "rarely overcome" (i.e., Rvi2, Rvi4, Rvi5, Rvi9, Rvi12, and Rvi14), ranging from 60 to $80 \%$. This indicated a high frequency of class 2 calls for all the corresponding differential hosts. If these calls really are compatible interactions, specific virulences are assumed to be present, but the corresponding isolates are not very aggressive and cannot yet effectuate resistance erosion. It could also be that the acquisition of these specific virulences may have a fitness cost. However, over time they may become more aggressive through directional selection, as observed previously for scab resistances in some hosts, such as $M$. floribunda, $M$. 'Mary Potter,' $M$. 'Professor Sprenger,' $M$. 'Sentinel,' and $M$. 'SugarTyme' (Beckerman et al. 2009).

The monitoring of resistance gene breakdowns in multiple sites provides the most comprehensive, nevertheless limited, picture of to what extent and where the different $R v i$ genes are currently overcome. The results of this analysis can be used by apple breeders in selecting gene combinations conferring more durable resistance. The limited breeding value of the Rvil, Rvi3, and Rvi8 genes is confirmed by the very high frequency of sites with resistance breakdown (83 to $100 \%$ ). Possibly, Rvilo could also be added to this group. Although this gene is rarely overcome considering its overall low

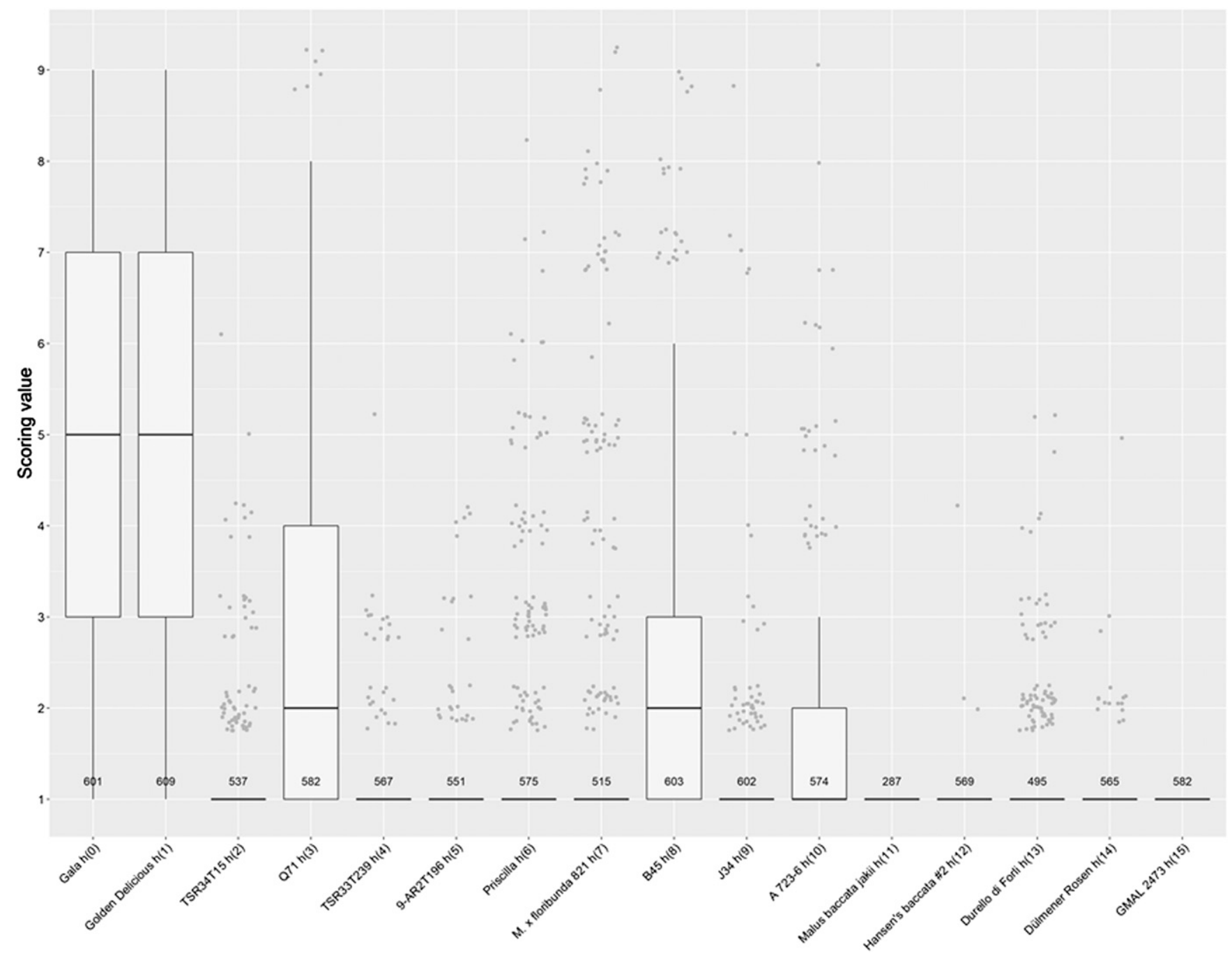

Fig. 1. Box plot of the scores observed over all years and sites for each of the 16 differential hosts. Severity class 1: No visible lesions; class 2: one or very few lesions detected upon close scrutiny of the tree $( \pm 1 \%$ of leaves affected); class 3 : immediately apparent lesions in general clustered in a few parts of the tree (1 to $5 \%$ of leaves affected); class 4 : intermediate; class 5: numerous lesions widespread over a large part of the tree $( \pm 25 \%)$; class 6 : intermediate; class 7 : severe infection with half of the leaves badly infected by multiple lesions $( \pm 50 \%)$; class 8 : intermediate $( \pm 75 \%)$; class 9 : tree completely affected with (nearly) all the leaves badly infected by multiple lesions $(>90 \%)$. The bold horizontal line represents the median value. The boxes cover $50 \%$ of the middle values while the whiskers each cover $\sim 25 \%$ of the more divergent values. The dots (outliers) are defined as values located at a distance from the median that is greater than two times the standard deviation. 
frequency of scores $>2$, the scorings emanated from more than half of the monitored sites (13 out of 23 sites). However, in four of the sites, there was only one score $>2$ (Fig. 2), and it may be too soon to give more definite advice on its use in breeding.

Applying the same criteria, the category of "rarely overcome genes" based on the total number of scores $>2$ could be further divided into two categories: those "sometimes overcome" (Rvi2, Rvi4, Rvi6, Rvi7, Rvi9, and Rvil3) and those rarely overcome (Rvi5, Rvi12, and Rvi14) over the sites. In the first group we find $R v i 2$, Rvi4, and $R v i 6$, which are probably the most commonly used scab resistance genes in apple breeding. Rvi2 and Rvi4 are combined in the cultivar Regia, whose resistance is already overcome (Peil et al. 2018), and elite parents with all three genes in homozygous state have been generated (Baumgartner et al. 2015). Because of the relative high frequency (about one third) of trap orchards with isolates that were virulent to these genes, we advise that they (including also $R v i 9$ and Rvil3) are used only in pyramids of at least three Rvis. As isolates combining avrRvi6 and avrRvi7 have been found (all those that generated infections on $\mathrm{h}(6,7)$ ), pyramids with these two genes should be avoided or complemented with at least two additional $R v i$ genes.

Resistance gene breakdown of Rvi5, Rvi12, and Rvil4 has rarely been encountered to date. These genes, together with Rvill and Rvil5, which so far have not been overcome, currently constitute the best sources of apple scab resistance, thus showing most promise for durable resistance. These findings agree with host (11) M. baccata 'Jackii,' as well as many other accessions, remaining scab-free or very rarely becoming infected in long-term disease monitoring projects (Beckerman et al. 2009; Den Boer and Green 1995). Nevertheless, at times these differential hosts do get infected to some extent (Bengtsson et al. 2000; Lefrancq and Lateur 2009; Sandskär and Liljeroth 2005), but probably only when infection conditions are optimal. In 2011, limited sporulation accompanied by chlorosis was observed on host (11) M. baccata 'Jackii' in Poland (Fig. 3). Reinoculation of $\mathrm{h}(11)$ with the strain that was isolated from an affected leaf showed the same symptoms of partial resistance, i.e., chlorosis with limited sporulation. Hence, the initial score of 3 was corrected to 1 .

Further research on the genetics of the differential hosts is required since some of these accessions, e.g., M. baccata 'Jackii' (h(11)),
Hansen's baccata \#2 (h(12)), and 'Dülmener Rosenapfel' (h(14)), carry more than one scab resistance gene (Soufflet-Freslon et al. 2008; Bus and Patocchi, unpublished data). Scoring of disease symptoms in this study may therefore underestimate infection frequencies of some genes, overestimating their breeding value. Further genetic analyses are in progress on these accessions in order to select single-gene differential hosts for $V$. inaequalis virulence monitoring in trap orchards.

The VINQUEST initiative has started well and the network continues to expand. To date, most of the collected data were contributed by European partners, while 15 partners in an additional nine countries are in the process of establishing their trap orchards. Finally, nine more partners in a further three countries have declared an interest in joining the initiative, but for different reasons have not yet done

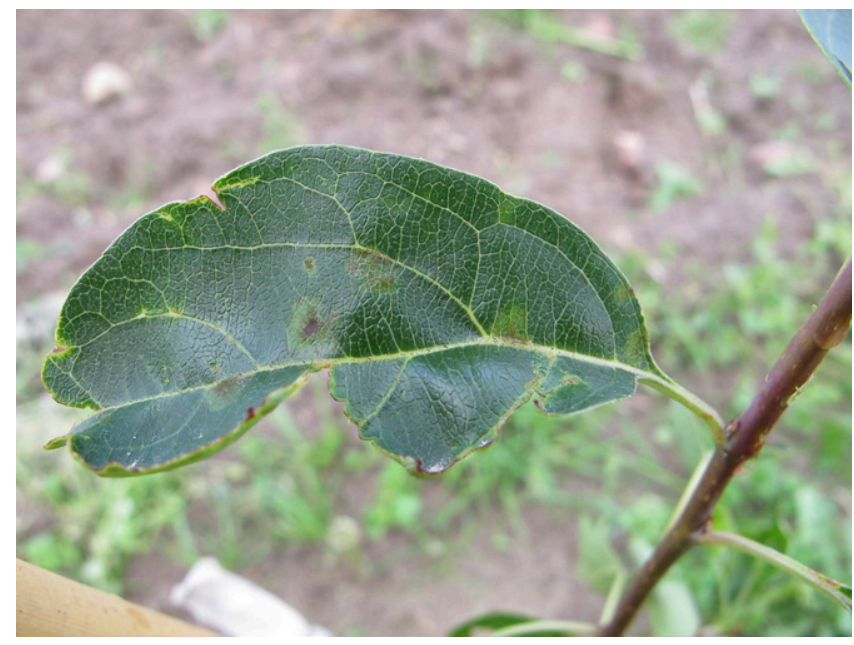

Fig. 3. Apple scab lesions on $h(11)$ Malus baccata 'Jackii' found in 2011 at Skierniewice (Poland). Although sporulation is obvious, this is accompanied by a resistance reaction (chlorosis) of the tree. The same reaction was obtained by artificial inoculation (data not shown). Such symptoms are not considered as a compatible interaction (abundant sporulation without reaction of the plant), and symptoms on this tree should therefore be called as severity score 1.
A

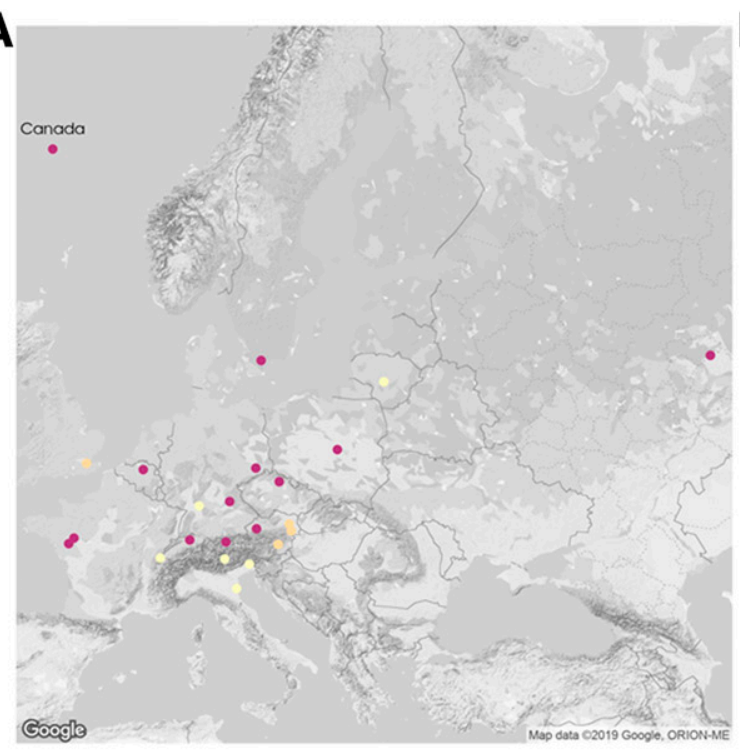

Scoring value $\quad 1 \quad=2 \quad>2$

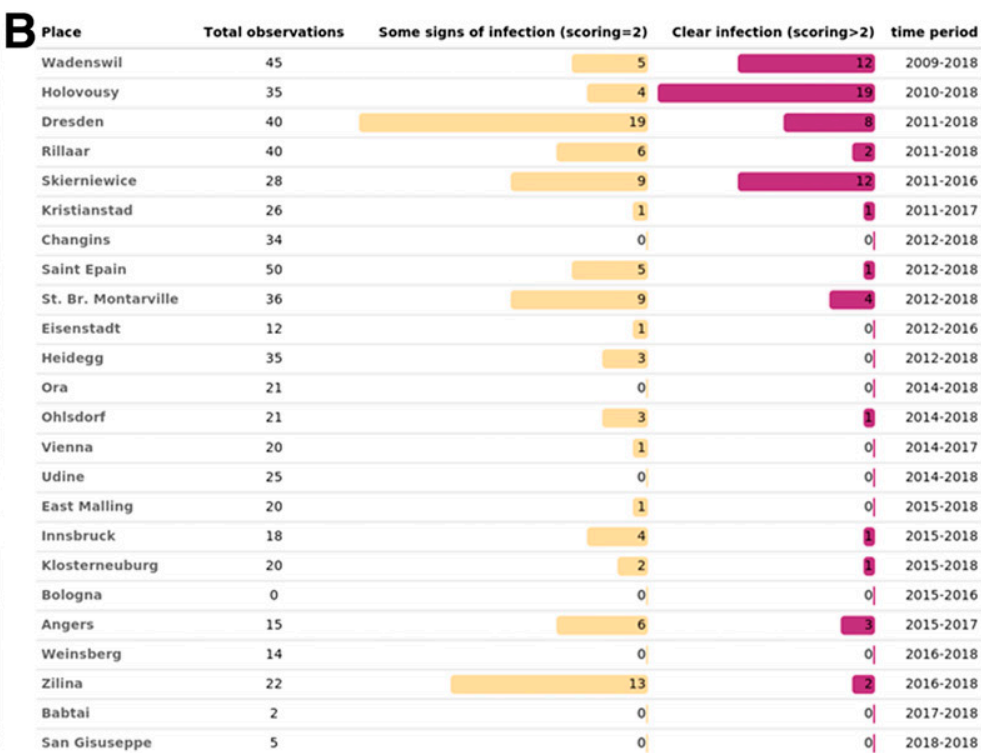

$2017 \cdot 2018$

Fig. 2. A, Resistance gene breakdown of Rvi10. Dots represent the geographic distribution of the VINQUEST partners providing data between 2009 and 2018 . For graphical reasons, Canada has been moved closer to Europe. Yellow dots: sites without observations of resistance gene breakdown. Orange dots: sites with observations never higher than severity score 2. Magenta dots: sites with at least one observation higher than severity score 2. B, Summary of the observations of Rvi10 resistance gene breakdown with severity scores $=2$ or $>2$ and indication of the periods when these observations were made. 
so. Partners in South and North America are awaiting the release of plant material from quarantine, while partners in Asia are at the orchard establishment phase. Therefore, a much more comprehensive global picture of the distribution of different virulences in $V$. inaequalis populations will become available in the future.

The results of the first 10 years of VINQUEST provide the first indications on which apple scab resistance genes show the most promise for breeding. However, since most of these genes do not occur in any commercial cultivars, they have not yet been exposed extensively to scab populations at large. Therefore, all the conclusions made for the different $R v i$ s should be considered as best-case scenarios, hence the deployment of resistance genes in pyramids only remains imperative to improve the chances of their durability. Of the five genes showing the most promise of achieving this, Rvi5 and Rvil4 are present in 'Murray' and 'Dülmener Rosenapfel' (recognizing that this cultivar carries multiple resistances), respectively, while Rvi15 is present in GMAL2473, a genotype producing relatively large apples. However, they all need further improvement for eating quality to meet today's breeder and consumer expectations. Nevertheless, they are at an advantage compared with the Rvill and Rvil2 genes, which are present in small-fruited wild apples, and so are expected to require more generations of backcrossing to improve both fruit size and quality. Some breeding programs have already performed several backcross cycles, but those still in the early stages would greatly benefit from using fast-breeding techniques, such as Fast-track (Volz et al. 2009) and the early flowering approach using the BpMADS4 gene (Flachowsky et al. 2011; Schlathölter et al. 2018) to accelerate the removal of undesired traits present in the donors of these two resistances. While not considered to produce a genetically modified plant in some countries, the application of this later new breeding technology defines it as a genetically modified plant in others (Bus et al. 2019).

\section{Acknowledgments}

The authors are very grateful to the additional VINQUEST partners, not listed in the paper, that are in the process of establishing their own differential orchards for future data contribution.

\section{Literature Cited}

Ayer, K. M., Villani, S. M., Choi, M. W., and Cox, K. D. 2019. Characterization of the VisdhC and VisdhD genes in Venturia inaequalis, and sensitivity to fluxapyroxad, pydiflumetofen, inpyrfluxam, and benzovindiflupyr. Plant Dis. 103:1092-1100.

Bastiaanse, H., Bassett, H. C. M., Kirk, C., Gardiner, S. E., Deng, C., Groenworld, R., Chagné, D., and Bus, V. G. M. 2016. Scab resistance in 'Geneva' apple is conditioned by a resistance gene cluster with complex genetic control. Mol. Plant Pathol. 17:159-172.

Baumgartner, I. O., Kellerhals, M., Costa, F., Dondini, L., Pagliarani, G., Gregori, R., Tartarini, S., Leumann, L., Laurens, F., and Patocchi, A. 2016. Development of SNP-based assays for disease resistance and fruit quality traits in apple (Malus $\times$ domestica Borkh.) and validation in breeding pilot studies. Tree Genet. Genomes 12:35.

Baumgartner, I. O., Patocchi, A., Frey, J. E., Peil, A., and Kellerhals, M. 2015. Breeding elite lines of apple carrying pyramided homozygous resistance genes against apple scab and resistance against powdery mildew and fire blight. Plant Mol. Biol. Report. 33:1573-1583.

Beckerman, J., Chatfield, J., and Draper, E. 2009. A 33-year evaluation of resistance and pathogenicity in the apple scab-crabapples pathosystem. HortScience 44:599-608

Beckerman, J. L., Sundin, G. W., and Rosenberger, D. A. 2015. Do some IPM concepts contribute to the development of fungicide resistance? Lessons learned from the apple scab pathosystem in the United States. Pest Manag. Sci. 71:331-342.

Bénaouf, G., and Parisi, L. 1997. Pathogenicity of Venturia inaequalis strains from Malus floribunda 821: comparison with race 6 on apple clones. Pages 8-11 in: Integrated Control of Pome Fruit Diseases. Proc. of 4th Workshop, Croydon, England, 19-23 August 1996. A. M. Berrie et al., eds. IOBC/WPRS Bulletin Vol. 20.

Bénaouf, G., and Parisi, L. 2000. Genetics of host-pathogen relationships between Venturia inaequalis races 6 and 7 and Malus species. Phytopathology 90:236-242.

Bengtsson, M., Lindhard, H., and Grauslund, J. 2000. Occurence of races of Venturia inaequalis in apple scab race screening orchard in Denmark. IOBC WPRS Bull. 23:225-229.

Brauns, M. 1962. Untersuchungen über die Resistenz der Sorte Antonowka und ihrer resistenten Nachkommen gegen den Erreger des Apfelschorfes. Der Züchter 32:297-304.
Broggini, G. A. L., Bus, V. G. M., Parravicini, G., Kumar, S., Groenwold, R., and Gessler, C. 2011. Genetic mapping of 14 avirulence genes in an EU-B04 × 1639 progeny of Venturia inaequalis. Fungal Genet. Biol. 48:166-176.

Bus, V. G. M., Bassett, H. C. M., Bowatte, D., Chagné, D., Ranatunga, C. A., Ulluwishewa, D., Wiedow, C., and Gardiner, S. E. 2010. Genome mapping of an apple scab, a powdery mildew and a woolly apple aphid resistance gene from open-pollinated Mildew Immune Selection. Tree Genet. Genomes $6: 477-487$

Bus, V. G. M., Bowen, J., Patocchi, A., Broggini, G. A. L., Kumar, S., and Laurens, F. N. D. 2019. Breeding fruit cultivars with durable resistance. Pages 233-274 in: Integrated Management of Insect Pests and Diseases of Tree Fruit. X. Xu and M. Fountain, eds. Burleigh Dodds Science Ltd. Publishing, Cambridge, UK.

Bus, V. G. M., Rikkerink, E. H. A., Caffier, V., Durel, C.-E., and Plummer, K. M. 2011. Revision of the nomenclature of the differential host-pathogen interactions of Venturia inaequalis and Malus. Annu. Rev. Phytopathol. 49: 391-413.

Bus, V. G. M., Van de Weg, W. E., Peil, A., Dunemann, F., Zini, E., Laurens, F. N. D., Blazek, J., Hanke, V., and Forsline, P. L. 2012. The role of Schmidt 'Antonovka' in apple scab resistance breeding. Tree Genet. Genomes 8: 627-642.

Caffier, V., Patocchi, A., Expert, P., Bellanger, M. N., Durel, C. E., HilberBodmer, M., Broggini, G. A. L., Groenwold, R., and Bus, V. G. M. 2015. Virulence characterization of Venturia inaequalis reference isolates on the differential set of Malus hosts. Plant Dis. 99:370-375.

Calenge, F., Faure, A., Goerre, M., Gebhardt, C., Van de Weg, W. E., Parisi, L., and Durel, C. E. 2004. Quantitative trait loci (QTL) analysis reveals both broad-spectrum and isolate-specific QTL for scab resistance in an apple progeny challenged with eight isolates of Venturia inaequalis. Phytopathology 94:370-379.

Chapman, K. S., Sundin, G. W., and Beckerman, J. L. 2011. Identification of resistance to multiple fungicides in field populations of Venturia inaequalis. Plant Dis. 95:921-926.

Clark, M. D. 2014. Characterizing the host response and genetic control in 'Honeycrisp' to apple scab (Venturia inaequalis). Ph.D. thesis, University of Minnesota, Minneapolis, MN. http://hdl.handle.net/11299/172140

Clark, M. D., Luby, J. J., Bradeen, J. M., and Bus, V. G. M. 2014. Identification of candidate genes at Rvil9 and Rvi20, two apple scab resistance loci in the 'Honeycrisp' apple (Malus $\times$ domestica). In: Plant and Animal Genome XXII Conference. Plant and Animal Genome.

Den Boer, J. H., and Green, T. L. 1995. Disease and aesthetic ratings. Malus 9: 8-58.

Dunemann, F., and Egerer, J. 2010. A major resistance gene from Russian apple 'Antonovka' conferring field immunity against apple scab is closely linked to the $V f$ locus. Tree Genet. Genomes 6:627-633.

Durel, C. E., Freslon, V., Denancé, C., Laurens, F., Lespinasse, Y., Rat, E., Parisi, L., Bus, V., Dapena de la Fuente, E., Miñarro, M., Bláquez, M. D., and Van de Weg, W. E. 2006. Genetic localisation of new major and minor pest and disease resistance factors in the apple genome. Page 25 in: 3rd International Rosaceae Genomics Conference, Napier, New Zealand.

Firko, M. 2014. Re: Request for confirmation that [ ] potato is not a regulated article. USDA-APHIS, Riverdale, MD. https://www.aphis.usda.gov/biotechnology/ downloads/reg_loi/aphis_response_cellectis_potato.pdf. Accessed 18 Mar 2020.

Flachowsky, H., Le Roux, P. M., Peil, A., Patocchi, A., Richter, K., and Hanke, M. V. 2011. Application of a high-speed breeding technology to apple (Malus $\times$ domestica) based on transgenic early flowering plants and markerassisted selection. New Phytol. 192:364-377.

Frederick, Z. A., Villani, S. M., Cooley, D. R., Biggs, A. R., Raes, J. J., and Cox, K. D. 2014. Prevalence and stability of qualitative Qol resistance in populations of Venturia inaequalis in the northeastern United States. Plant Dis. 98:1122-1130.

Gardiner, S. E., Bowatte, D., Bassett, H. M., Scheper, R. W. A., Walter, M., Rijken, H., Campbell, R., Kitson, B., Turner, L., Fischer, B., Johnston, S. L., Deng, C., Wu, C., Singla, G., Jesson, L. K., Hedderley, D., Chagné, D., and Bus, V. G. M. 2018. Genetic mapping of novel loci for resistance to European canker and apple scab. Page 36 in: 9th International Rosaceae Genomics Conference, Nanjing, China.

Gregoire, M. C. 2011. Re: APHIS confirmation of the regulatory status of null segregant (NS) lines derived from genetically engineered (GE) plants in an accelerated tobacco breeding program. USDA-APHIS, Riverdale, MD. https://www.aphis.usda.gov/biotechnology/downloads/reg_loi/Dr\%20Ramsey $\% 20$ S\%20Lewis\%20NCSC\%20Final.pdf. Accessed 18 Mar 2020.

Holb, I. J. 2006. Effect of six sanitation treatments on leaf litter density, ascospore production of Venturia inaequalis and scab incidence in integrated and organic apple orchards. Eur. J. Plant Pathol. 115:293-307.

Holb, I. J. 2007. Effect of four non-chemical sanitation treatments on leaf infection by Venturia inaequalis in organic apple orchards. Eur. J. Hortic. Sci. 72:60-65.

Igarashi, M., Hatsuyama, Y., Harada, T., and Fukasawa-Akada, T. 2016 Biotechnology and apple breeding in Japan. Breed. Sci. 66:18-33.

Jänsch, M., Broggini, G. A. L., Weger, J., Bus, V. G. M., Gardiner, S. E., Bassett, H., and Patocchi, A. 2015. Identification of SNPs linked to eight apple disease resistance loci. Mol. Breed. 35:45. 
Khajuria, Y. P., Kaul, S., Wani, A. A., and Dhar, M. K. 2018. Genetics of resistance in apple against Venturia inaequalis (Wint.). Cke. Tree Genet. Genomes 14:16.

Kosman, E., Ben-Yehuda, P., Manisterski, J., and Sela, H. 2019. Diversity of virulence phenotypes among annual populations of Puccinia triticina originating from common wheat in Israel during the period 2000-15. Plant Pathol. 68:1741-1748.

Lefrancq, B., and Lateur, M. 2009. Monitoring and occurrence of new races of Venturia inaequalis on apple in Belgium. Commun. Agric. Appl. Biol. Sci. 74:623-631.

Lespinasse, Y. 1989. Breeding pome fruits with stable resistance to diseases. 3. Genes, resistance mechanisms, present work and prospects. IOBC WPRS Bull. 12:100-115.

Lespinasse, Y. 1994. Apple scab resistance and durability. New races and strategies for the future. Pages 105-106 in: Progress in Temperate Fruit Breeding. H. Schmidt and M. Kellerhals, eds. Kluwer Academic Publishers, Dordrecht, NL.

Mac an tSaoir, S., Cooke, L. R., and Mc Cracken, A. R. 2010. The effects of leaf litter treatments, post-harvest urea and omission of early season fungicide sprays on the overwintering of apple scab on Bramley's Seedling grown in a maritime environment. Irish J. Agric. Food Res. 49:55-66.

MacHardy, W. E. 1996. Apple scab. Biology, Epidemiology and Management. The American Phytopathological Society, St. Paul, MN.

Manktelow, D. W. L., Beresford, R. M., Batchelor, T. A., and Walker, J. T. S. 1996. Use patterns and economics of fungicides for disease control in New Zealand apples. Acta Hortic. 422:187-192.

McGarry, R. C., Klocko, A. L., Pang, M. X., Strauss, S. H., and Ayre, B. G. 2017. Virus-induced flowering: An application of reproductive biology to benefit plant research and breeding. Plant Physiol. 173:47-55.

Paczos-Grzeda, E., and Sowa, S. 2019. Virulence structure and diversity of Puccinia coronata f. sp. avenae P. Syd. \& Syd. in Poland during 2013 to 2015. Plant Dis. 103:1559-1564.

Papp, D., Singh, J., Gadoury, D. M., and Khan, A. 2020. New North American isolates of Venturia inaequalis can overcome apple scab resistance of Malus floribunda 821. Plant Dis. 104:649-655.

Parisi, L., Fouillet, V., Schouten, H. J., Groenwold, R., Laurens, F., Didelot, F., Evans, K., Fischer, C., Gennari, F., Kemp, H., Lateur, M., Patocchi, A., Thissen, J., and Tsipouridis, C. 2004. Variability of the pathogenicity of Venturia inaequalis in Europe. Acta Hortic. 663:107-114.

Patocchi, A., Frei, A., Frey, J. E., and Kellerhals, M. 2009. Towards improvement of marker assisted selection of apple scab resistant cultivars: Venturia inaequalis virulence surveys and standardization of molecular marker alleles associated with resistance genes. Mol. Breed. 24:337-347.

Peil, A., Patocchi, A., Hanke, M.-V., and Bus, V. G. M. 2018. Apple cultivar Regia possessing both Rvi2 and Rvi4 resistance genes is the source of a new race of Venturia inaequalis. Eur. J. Plant Pathol. 151:533-539.
Pikunova, A., Madduri, M., Sedov, E., Noordijk, Y., Peil, A., Troggio, M., Bus, V. G. M., Visser, R. G. F., and van de Weg, E. 2014. 'Schmidt's Antonovka' is identical to 'Common Antonovka', an apple cultivar widely used in Russia in breeding for biotic and abiotic stresses. Tree Genet. Genomes 10:261-271.

Porsche, F. M., Pfeiffer, B., and Kollar, A. 2017. A new phytosanitary method to reduce the ascospore potential of Venturia inaequalis. Plant Dis. 101:414-420.

Roberts, A. L., and Crute, I. R. 1994. Apple scab resistance from Malus floribunda 821 (Vf) is rendered ineffective by isolates of Venturia inaequalis from Malus floribunda. Nor. J. Agric. Sci. 17:404-406.

Sandskär, B., and Liljeroth, E. 2005. Incidence of races of the apple scab pathogen (Venturia inaequalis) in apple growing districts in Sweden.Acta Agric. Scand. Sect. B-Soil Plant Sci. 55:143-150.

Schlathölter, I., Jänsch, M., Flachowsky, H., Broggini, G. A. L., Hanke, M.-V., and Patocchi, A. 2018. Generation of advanced fire blight-resistant apple (Malus $\times$ domestica) selections of the fifth generation within 7 years of applying the early flowering approach. Planta 247:1475-1488.

Soriano, J., Madduri, M., Schaart, J., van der Burgh, A., van Kaauwen, M. W. Tomic, L., Groenwold, R., Velasco, R., van de Weg, E., and Schouten, H. 2014. Fine mapping of the gene Rvil8 (V25) for broad-spectrum resistance to apple scab, and development of a linked SSR marker suitable for markerassisted breeding. Mol. Breed. 34:2021-2032.

Soriano, J. M., Joshi, S. G., van Kaauwen, M., Noordijk, Y., Groenwold, R., Henken, B., van de Weg, W. E., and Schouten, H. J. 2009. Identification and mapping of the novel apple scab resistance gene $V d 3$. Tree Genet. Genomes 5:475-482.

Soufflet-Freslon, V., Gianfranceschi, L., Patocchi, A., and Durel, C. E. 2008. Inheritance studies of apple scab resistance and identification of Rvi14, a new major gene that acts together with other broad-spectrum QTL. Genome 51: 657-667.

van den Bosch, F., Lopez-Ruiz, F., Oliver, R., Paveley, N., Helps, J., and van den Berg, F. 2018. Identifying when it is financially beneficial to increase or decrease fungicide dose as resistance develops. Plant Pathol. 67:549-560.

Vanderzande, S., Piaskowski, J. L., Luo, F., Edge-Garza, D. A., Klipfel, J., Schaller, A., Martin, S., and Peace, C. 2018. Crossing the finish line: How to develop diagnostic DNA tests as breeding tools after QTL discovery. J. Hortic. 5:228.

Volz, R. K., Rikkerink, E., Austin, P., Lawrence, T., and Bus, V. G. M. 2009 "Fast-breeding" in apple: a strategy to accelerate introgression of new traits into elite germplasm. Acta Hortic. 814:163-168.

Williams, E. B., and Brown, A. G. 1968. A new physiologic race of Venturia inaequalis, incitant of apple scab. Plant Dis. Rep. 52:799-801.

Williams, E. B., and Shay, J. R. 1957. The relationship of genes for pathogenicity and certain other characters in Venturia inaequalis (Cke.) Wint. Genetics 42 704-711.

Zini, E. 2005. Construzione di una mappa di associazione della popolazione di melo 'Golden Delicious' $\times$ 'Freedom' e caratterizzazione del gene di resistenza Va a ticchiolatura. Ph.D. thesis, University of Bologna, Bologna, Italy. 